Pesq. Vet. Bras. 30(5):443-446, maio 2010

\title{
Anticorpos IgG anti-Neospora caninum e Toxoplasma gondii em búfalas (Bubalus bubalis) criadas no estado do Pará1
}

\author{
Sandro P. Silva ${ }^{2}$, Rinaldo A. Mota ${ }^{3}$, Eduardo B. Faria ${ }^{3}$, Erika F.T.S. \\ Fernandes ${ }^{3}$, Orestes L.S. Neto ${ }^{3}$, Pedro P.F. Albuquerque ${ }^{3}$ e Hilma L.T. Dias ${ }^{2}$ \\ ABSTRACT.- Silva S.P., Mota R.A., Faria E.B., Fernandes E.F.T.S., Neto O.L.S., Albu- \\ querque P.P.F. \& Dias H.L.T. 2010 [Occurrence of IgG antibodies anti-Neospora cani- \\ num and Toxoplasma gondii in female water buffaloes (Bubalus bubalis) raised in \\ the Brazilian state of Pará.] Anticorpos IgG anti-Neospora caninume Toxoplasma gondii \\ em búfalas (Bubalus bubalis) criadas no estado do Pará. Pesquisa Veterinária Brasileira \\ 30(5):443-446. Laboratório de Investigação e Diagnóstico de Enfermidades Animais, Uni- \\ versidade Federal do Pará, Belém, PA, Brazil. E-mail: spatroca@ yahoo.com.br \\ To investigate the occurrence of antibodies IgG anti-Neospora caninum and Toxoplasma \\ gondii, blood samples were collected from 374 adult female water buffaloes originated from \\ 14 production units located in 13 counties of the state of Pará. The sera were subjected to \\ indirect fluorescent antibody (IFA), using titers of 200 and 64 as IFA cut off points for $N$. \\ caninum and T. gondii, respectively. Hundred and fifty three (40.9\%) buffaloes were sero- \\ positive for $N$. caninum, with $100 \%$ of the properties being sources of infection. Four buffaloes \\ (1.1\%) in four farms were seropositive for T. gondii, and one buffalo cow $(0.27 \%)$ was seropositive \\ for the two parasites. The presence of antibodies indicates that these protozoan parasites \\ are circulating among buffaloes from the properties studied, representing a source of infection \\ to other animals, as well as a possible cause of reproductive disorders in this species.
}

INDEX TERMS: Neosporosis, toxoplasmosis, serology, buffaloes, indirect fluorescent antibody.

RESUMO.- Para determinar a ocorrência de anticorpos IgG anti-Neospora caninum e Toxoplasma gondii em 14 unidades produtivas de búfalos, situadas em 13 municípios no estado do Pará, foram coletadas amostras de soro sanguíneo de 374 fêmeas adultas. Os soros foram submetidos à reação de imunofluorescência indireta (RIFI), utilizando-se os títulos 200 e 64, respectivamente como ponto de corte para N. caninume T. gondii. Obteve-se $153(40,9 \%)$ de animais soropositivos para $N$. caninum com $100 \%$ das propriedades com focos da infecção, enquanto que quatro búfalas $(1,1 \%)$ foram soropositivas em quatro fazendas para $T$. gondii e uma búfala $(0,27 \%)$ foi soropositiva para ambos parasitos. A presença de anticorpos é um indicativo da circulação des-

\footnotetext{
${ }^{1}$ Recebido em 13 de novembro de 2009.

Aceito para publicação em 4 de janeiro de 2010.

${ }^{2}$ Laboratório de Investigação e Diagnóstico de Enfermidades Animais, Centro de Ciências Biológicas, Universidade Federal do Pará (UFPA), Rua Augusto Corrêa 1, Guamá, Cx. Postal 479, Belém, PA 66075-110, Brasil. Autor para correspondência: spatroca@yahoo.com.br

${ }^{3}$ Laboratório de Bacterioses, Departamento de Medicina Veterinária, Universidade Federal Rural de Pernambuco (UFRPE), Rua Dom Manoel de Medeiros s/n, Dois Irmãos, Recife, PE 52171-900, Brasil.
}

ses protozoários em búfalos das propriedades estudadas, representando uma fonte de infecção para outros animais, assim como o possível envolvimento em distúrbios reprodutivos nessa espécie.

TERMOS DE INDEXAÇÃO: Neosporose, toxoplasmose, sorologia, bubalinos, reação de imunofluorescência indireta.

\section{INTRODUÇÃO}

Neospora caninum e Toxoplasma gondii são protozoários que apresentam características parecidas e estão amplamente distribuídos pelo mundo. No entanto diferem quanto ao hospedeiro definitivo. Ambos são parasitos intracelulares obrigatórios e podem acometer diversas espécies de animais como caprinos, bovinos e bubalinos (Dubey 1994, Huong et al. 1998, Gondim et al. 1999, Faria et al. 2007).

A principal sintomatologia observada em fêmeas bovinas infectadas com $N$. caninum é o abortamento que ocorre principalmente entre o quinto e sétimo mês de gestação, sendo que fêmeas soropositivas estão mais sujeitas ao abortamento que as soronegativas (Dubey 2003, Campero et al. 2003). No entanto, ainda não foi demonstrada a impor- 
tância do $N$. caninum como causador de abortamento em búfalas, porém, não se descarta esta possibilidade, sendo necessárias investigações sobre a ação deste agente em doenças reprodutivas nessa espécie (Gondim et al. 2007).

Levantamentos sorológicos realizados no Egito, Vietnã e Itália demonstraram anticorpos contra $N$. caninum em búfalos (Dubey et al. 1998, Huong et al. 1998, Guarino et al. 2000). Trabalhos realizados no Brasil, nos estados de São Paulo, Pará e Bahia também encontraram búfalos soropositivos para N. caninum (Fujii et al. 2001, Souza et al. 2001, Gennari et al. 2005, Gondim et al. 2007). T. gondii também pode causar abortamento em bovinos, no entanto, este sinal clínico não tem sido indicado como importante nessa espécie (Dubey et al. 1986).

Foram demonstrados anticorpos contra $T$. gondii em búfalos no Vietnã e Irã (Huong et al. 1998, Navidpour \& Hoghooghi-Rad, 1998). No Brasil, anticorpos contra $T$. gondii nessa espécie já foram demonstrados na Bahia (Gondim et al. 1999), no Pará (Barros et al. 1999) e em São Paulo (Fujii et al. 2001, Souza et al. 2001)

Devido a importância da bubalinocultura para o estado do Pará e os poucos trabalhos envolvendo essa espécie, objetivou-se estudar a ocorrência de anticorpos IgG anti- $N$. caninum e anti-T. gondii em búfalas criadas nesse Estado.

\section{MATERIAL E MÉTODOS}

Para o presente estudo foram coletadas aleatoriamente 374 amostras de fêmeas bubalinas com idade entre dois a dez anos das raças Murrah, Mediterrâneo, Carabao, Jafarabadi e seus mestiços. As amostras foram coletadas em 14 propriedades rurais pertencentes a 13 municípios no estado do Pará (Quadro 1).

Após contenção dos animais, o sangue foi coletado por meio de venopunção da jugular. O sangue coletado foi centrifugado para a obtenção do soro sangüíneo que foram estocados em microtubos de polipropileno (tipo Eppendorf) previamente identificados e mantidos a $-20^{\circ} \mathrm{C}$ até o momento da realização das provas sorológicas.

Os testes foram realizados no Laboratório de Bacterioses do Departamento de Medicina Veterinária da Universidade Federal Rural de Pernambuco (UFRPE), seguindo o protocolo descrito por Souza et al. (2001) para pesquisa de imunoglobulinas $\mathrm{G}$ anti-Neospora caninum e Camargo (1974) para a detecção das imunoglobulinas $\mathrm{G}$ anti-Toxoplasma gondii através da Reação de Imunofluorescência Indireta (RIFI). Considerou-se o título 200 e 64 como pontos de corte para $N$. caninum e $T$. gondii, respectivamente.

Para a detecção de anticorpos anti- $N$. caninum utilizou-se taquizoítos da cepa NC-1, obtidos através de cultura in vitro em células VERO. Para a pesquisa de anticorpos anti-T. gondii utilizou-se taquizoítos da cepa $\mathrm{RH}$ obtidas através de lavado peritoneal de camundongos experimentalmente infectados.

Foram utilizados soros controle positivo e negativo para $N$. caninum e $T$. gondii previamente conhecidos, assim como conjugado anti-lgG bovino (molécula inteira com FITC, produzido em coelhos, Sigma/F-7887).

As amostras foram submetidas a diluições seriadas de razão dois até a obtenção da maior diluição positiva na RIFI. A leitura foi realizada em microscópio de fluorescência com aumento de 40x. Foi considerada como reação positiva a fluorescência periférica total dos taquizoítos. O título do soro foi a recíproca da maior diluição que apresentou resultado positivo.
Quadro 1. Freqüência de anticorpos anti-Neospora caninum em búfalas sororreagentes e não sororreagentes na RIFI, de acordo com as propriedades rurais e municípios do estado do Pará

\begin{tabular}{lcccccc}
\hline \multicolumn{1}{c}{ Município } & \multicolumn{2}{c}{$\begin{array}{c}\text { Animais } \\
\text { sororreagentes }\end{array}$} & & \multicolumn{2}{c}{$\begin{array}{c}\text { Animais não } \\
\text { sororreagentes }\end{array}$} & Total \\
\cline { 2 - 3 } & No & $\%$ & & № & $\%$ & \\
\cline { 1 - 2 } Xinguara & 19 & 38 & & 31 & 62 & 50 \\
Altamira & 10 & 50 & & 10 & 50 & 20 \\
Salvaterra (Fazenda 1) & 14 & 48,28 & & 15 & 51,72 & 29 \\
Santa Izabel do Pará & 11 & 84,62 & & 02 & 15,38 & 13 \\
Oriximina & 24 & 80 & & 06 & 20 & 30 \\
São Caetano de Odivelas & 03 & 42,86 & & 04 & 57,14 & 07 \\
Moju & 11 & 47,83 & & 12 & 52,17 & 23 \\
Soure & 11 & 34,38 & & 21 & 65,62 & 32 \\
Cachoeira do Arari & 03 & 25 & & 09 & 75 & 12 \\
Ponta de Pedras & 10 & 52,63 & & 09 & 47.37 & 19 \\
Peixe-boi & 13 & 29,55 & & 31 & 70,45 & 44 \\
Ipixuna do Parán & 09 & 32,14 & & 19 & 67,86 & 28 \\
Salvaterra (Fazenda 2$)$ & 02 & 8 & & 23 & 92 & 25 \\
Nova Timboteua & 13 & 30,95 & & 29 & 69,05 & 42 \\
Total & 153 & 40,91 & & 221 & 59,09 & 374
\end{tabular}

Este é um estudo de corte transversal onde os dados foram tabulados e tratados estatisticamente pelo percentual simples para verificar a presença de anticorpos $\lg G$ anti- $N$. caninum e anti-T. gondii em fêmeas bubalinas do estado do Pará. A diferença entre as propriedades foi verificada pelo teste de Qui-quadrado $\left(\chi^{2}\right)$, quando possível, ou através do teste exato de Fischer, tendo nível alfa de 0,05 e utilizando o software BioEstat 5.0 (Ayres et al. 2007).

\section{RESULTADOS}

Do total de 374 amostras analisadas, observou-se que 153 $(40,91 \%)$ foram positivas para IgG anti-Neospora caninum e $221(59,09 \%)$ foram negativas. Os títulos de anticorpos nas 153 búfalas positivas foram: $200(40,52 \%), 400(22,88 \%)$, $800(20,92 \%), 1600(9,15 \%)$ e 3200 (6,54\%). (Quadro 1)

Em relação às propriedades obteve-se $100 \%$ dos rebanhos analisados positivos, uma vez que todas as 14 fazendas apresentaram pelo menos um animal positivo com freqüência variando de $8 \%$ a $84,62 \%$, sendo que as mesmas tiveram diferença significativa $(p<0,05)$ quando comparadas entre si.

Na pesquisa de anticorpos IgG anti-Toxoplasma gondii, quatro $(1,1 \%)$ búfalas foram positivas, enquanto que $370(98,9 \%)$ foram negativas. Três búfalas apresentam título 64 e uma 128.

Dentre as 14 propriedades rurais testadas, quatro tiveram pelo menos uma búfala reagente, representando $28,6 \%$ das fazendas estudadas, enquanto que 11 não tiveram nenhuma búfala positiva, não havendo diferença significativa $(p>0,05)$ entre as propriedades analisadas.

\section{DISCUSSÃO}

Quando comparado a outros trabalhos realizados com a espécie bubalina, observou-se que os resultados para anticorpos anti-Neospora canunum obtidos nesse estudo foi superior ao descrito por Guarino et al. (2000) na Itália, com $34,6 \%$ dos búfalos positivos na RIFI, com ponto de corte 200. Quando considerado o resul- 
tados obtido por Dubey et al. (1998) no Egito (68\%), os resultados desse estudo foi inferior, no entanto, os mesmos utilizaram o teste de aglutinação direta. $\mathrm{Na}$ Argentina, Campero et al. (2007) encontraram uma freqüência de $64 \%$ dos búfalos positivos, contudo foi usado o porto de corte 100 na RIFI.

No Brasil, freqüência menor de animais positivos foi demonstrado por Gondim et al. (1999) que evidenciaram $36,5 \%$ de búfalos positivos, e quase uma década depois Gondim et al. (2007) descreveram freqüência 35,9\%, sendo ambos os trabalhos realizados em búfalos oriundos da Bahia com ponto de corte 200 na RIFI.

Valores superiores foram observados em São Paulo por Souza et al. (2001) que verificaram $56,0 \%$ de positividade com ponto de corte 200, Fujii et al. (2001) que encontraram soroprevalência de $64 \%$ com ponto de corte 25 na RIFI. Ainda em São Paulo, Rodrigues et al. (2005) detectaram $79 \%$ de búfalos reagentes, e no estado do Pará Gennari et al. (2005) encontraram freqüência de $70,9 \%$, sendo que em ambos os estudos foram utilizados ponto de corte 25 na RIFI.

A falta de uma padronização quanto ao ponto de corte na RIFI, assim como o uso de diferentes técnicas, pode dificultar ou até mesmo impossibilitar a comparação dos resultados obtidos em diferentes trabalhos. De acordo com Dubey (2003), a RIFI não apresenta um ponto de corte definitivo que se justifica pela dificuldade de diferenciar sorologicamente animais cronicamente infectados de animais com infecção aguda.

Todas as propriedades possuíam cães que tinham livre acesso às pastagens das búfalas, porém não foi possível analisar sorologicamente estes animais. De acordo com McAllister et al. (1998), o cão é o hospedeiro definitivo de Neospora caninum e é considerado um fator de risco para a infecção.

López-Gatius et al. (2004) consideram a transmissão vertical de $N$. caninum como a principal rota de infecção em rebanhos bovinos, que não apresentem cães, colaborando significativamente para manutenção da infecção dentro do rebanho. Entretanto os autores não excluíram a possibilidade de infecção por animais silvestres.

A via vertical, também pode ser responsável pela manutenção do parasito em rebanhos bubalinos, visto que Rodrigues et al. (2004), demonstraram em bezerros búfalos com um dia de vida, a presença de anticorpos anti- $N$. caninum, sendo um indicativo de infecção neonatal (Rodrigues et al. 2004).

No que se refere a Toxoplasma gondii, resultados obtidos foram semelhantes aos observados por Huong et al. (1998) no Vietnã, onde a prevalência foi de $3 \%$, porém neste estudo foi utilizado o teste de aglutinação direto (DAT), Gondim et al. (1999) no Brasil (Bahia) encontraram uma frequência de 3,85\%, utilizando o teste de aglutinação em látex (LAT).

No Pará, Barros et al. (1999), observaram 12,2\% (15/ 123) e $22,8 \%$ (28/123) de búfalos reagentes no Ensaio Imunoenzimático (ELISA) e Teste de Aglutinação em Látex (LAT), respectivamente.

Resultados com porcentagem maior de animais reagentes tem sido descritos. Em testes com uso de RIFI realizados em búfalos no Irã (Navidpour \& Hoghooghi-Rad 1998) e em São Paulo (Souza et al. 2001), foram encontrados respectivamente com 8,8\% ( $\geq 16)$ e 49,9\% ( $\geq 64)$ de animais reagentes para anticorpos anti- $T$. gondii.

Na presente pesquisa, apenas uma $(0,27 \%)$ búfala apresentou anticorpos IgG anti- $N$. caninum e anti- $T$. gondii na RIFI com títulos 200 e 64, respectivamente. Não se observou associação entre a infecção em búfalas por ambos os agentes.

\section{CONCLUSÃO}

Anticorpos anti-Neospora caninum e anti-Toxoplasma gondii foram demonstrados em búfalas no estado do Pará, sendo a segunda descrição na espécie bubalina para ambos os agentes. A presença de anticorpos é um indicativo da circulação desses protozoários nas propriedades estudadas, representando um risco para a saúde pública e uma fonte de infecção para outros animais, assim como um possível envolvimento em distúrbios reprodutivos nessa espécie.

\section{REFERÊNCIAS}

Ayres M., Ayres J.R.M., Ayres D.L. \& Santos A.S. 2007. BioEstat 5.0-Aplicações Estatísticas nas Áreas das Ciências Biológicas e Médicas: Sociedade Civil Mamirauá, Belém. CNPq, Brasília. 290p.

Barros A.A.M., Molnár E., Carvalho M. \& Molnár L. 1999. ELISA e latex-aglutinação utilizados para detectar anticorpos anti-Toxoplasma gondii em diferentes animais domésticos. Anais $20^{\circ}$ Congresso Brasileiro de Microbiologia, Sociedade Brasileira de Microbiologia, Salvador, BA, p.143.

Camargo M.E. 1974. Introdução às técnicas de imunofluorescência. Revta Bras. Patologia Clínica 10:87-107.

Campero C.M., Moore D.P., Odeón A.C., Cipolla A.L. \& Odriozola E. 2003. Aetiology of bovine abortion in Argentina. Vet. Res. Commun. 27:359-369.

Campero C.M., Pérez A., Moore D.P., Crudeli G., Benitez D., Draghi M.G., Cano D., Konrad J.L. \& Odeón A.C. 2007. Occurrence of antibodies against Neospora caninum in water buffaloes (Bubalus bubalis) on four ranches in Corrientes province, Argentina. Vet. Parasitol. 150:155-158

Dubey J.P. 1986. A review of toxoplasmosis in cattle. Vet. Parasitol. 22:177-202.

Dubey J.P. 1994. Toxoplasmosis. J. Am. Vet. Med. Assoc. 205:15931598.

Dubey J.P. 2003. Review of Neospora caninum and neosporosis in animals. Korean J. Parasitol. 41:1-16.

Dubey J.P., Romand S., Hilali M., Kwok O.C.H. \& Thulliez P. 1998. Seroprevalence of antibodies to Neospora caninum and Toxoplasma gondii in water buffaloes (Bubalus bubalis) from Egypt. Int. J. Parasitol. 28:527-529.

Faria E.B., Gennari S.M., Pena H.F.J., Athayde A.C.R., Silva M.L.C.R. \& Azevedo S.S. 2007. Prevalence of anti-Toxoplasma gondii and anti-Neospora caninum antibodies in goats slaughtered in the public slaughterhouse of Patos city, Paraíba State, Northeast region of Brazil. Vet. Parasitol. 149:126-129.

Fujii T.U., Kasai N., Nishi S.M., Dubey J.P. \& Gennari S.M. 2001. Seroprevalence of Neospora caninum in female water buffaloes (Bubalus bubalis) from the southeastern region of Brazil. Vet. Parasitol. 99:331334.

Gennari S.M., Rodrigues A.A.R., Viana R.B. \& Cardoso E.C. 2005. Occurrence of anti-Neospora caninum antibodies in water buffaloes 
(Bubalus bubalis) from the Northern region of Brazil. Vet. Parasitol. 134:169-171.

Gondim L.F.P., Barbosa Jr H.V., Ribeiro Filho C.H.A. \& Saeki H. 1999. Serological survey of antibodies to Toxoplasma gondii in goats, sheep, cattle and water buffaloes in Bahia State, Brazil. Vet. Parasitol. 82:273276.

Gondim L.F.P., Pinheiro A.M. \& Almeida M.A.O. 2007. Freqüência de anticorpos anti-Neospora caninum em búfalos (Bubalus bubalis) criados no estado da Bahia. Revta Bras. Saúde Prod. Anim. 8:92-96.

Guarino A., Fusco G., Savini G., Di Francesco G. \& Cringoli G. 2000. Neosporosis in water buffalo (Bubalus bubalis) in southern Italy. Vet. Parasitol. 91:15-21.

Huong L.T.T., Ljungstrom B.L.L., Uggla A. \& Bjorkman, C. 1998. Prevalence of antidodies to Neospora caninum and Toxoplasma gondii in cattle and buffaloes in southern Vietnam. Vet. Parasitol. 75:53-57.

López-Gatius F., López-Béjar M., Murugavel K., Pabón M., Ferrer D. \& Almería S. 2004. Neospora-associated abortion episode over a 1-year period in a dairy herd in north-east Spain. J. Vet. Med. 51:348-352.
McAllister M.M., Dubey J.P., Lindsay D.S., Jolley W.R., Wills R.A. \& McGuire A.M. 1998. Dogs are definitive hosts of Neospora caninum. Int. J. Parasitol. 28:1473-1478.

Navidpour S. \& Hoghooghi-Rad N. 1998. Seroprevalence of anti-Toxoplasma gondii antibodies in buffaloes in Khoozestan province, Iran. Vet. Parasitol. 77:191-194.

Rodrigues A.A.R., Gennari S.M., Aguiar D.M., Sreekumar C., Hill D. E., Miska K.B., Vianna M.C.B. \& Dubey J.P. 2004. Shedding of Neospora caninum oocysts by dogs fed tissues from naturally infected water buffaloes (Bubalus bubalis) from Brazil. Vet. Parasitol. 124:139-150.

Rodrigues A.A.R., Gennari S.M., Paula V.S.O., Aguiar D.M., Fujii T.U., Starke-Buzeti W., Machado R.Z. \& Dubey J.P. 2005. Serological responses to Neospora caninum in experimentally and naturally infected water buffaloes (Bubalus bubalis). Vet. Parasitol. 129:21-24.

Souza L.M., Nascimento A.A., Furuta P.I., Basso L.M.S., Silveira D.M. \& Costa A.J. 2001. Detecção de anticorpos contra Neospora caninum e Toxoplasma gondii em soros de bubalinos (Bubalus bubalis) no Estado de São Paulo, Brasil. Ciênc. Agrárias 22:39-48. 